\title{
Seasonal changes in growth and energy status in the Third World
}

\author{
BY ANDREW M. PRENTICE AND TIMOTHY J. COLE \\ MRC Dunn Nutrition Unit, Milton Road, Cambridge CB4 $1 X J$
}

\begin{abstract}
Affluent, technically advanced societies have escaped from the effects of nutritional seasonality by means of a cash economy, modern food processing and storage techniques, and worldwide transportation of foodstuffs. However, there remain many areas of the world which are still vulnerable to seasonal food shortages caused by winters or dry seasons when crops cannot be grown. Seasonality is of interest both in its own right as it still affects millions of the world's poor, but also as a possible forerunner of some of the most widespread diseases of affluence through its influence on the evolution of 'thrifty' metabolic traits which have become dangerously redundant in populations which are no longer subjected to food shortages. The present paper describes the profound effects of seasonality on child growth and adult energy status mediated through changes in food intake, work patterns and infection rates.
\end{abstract}

\section{GLOBAL DISTRIBUTION OF SEASONALITY}

Ferro-Luzzi et al. (1988) have mapped out the areas of varying seasonality in the Third World. Severe seasonality is confined to the southern edge of the Sahara and round into the Horn of Africa, to parts of southern Africa around the Kalahari, to north-west India, and to a few small areas of South America. There is a gradually lessening severity of seasonality around these major foci. Such data are difficult to pull together and this summary probably misses some important areas, particularly of winter seasonality in wide areas of Asia.

Fig. 1 shows the Ferro-Luzzi \& Branca (1993) compilation from the available literature of seasonal swings in body weight. There seems to be little difference in weight loss between men and women, and on the whole the swings are not very great in spite of the fact that most of these studies specifically set out to investigate seasonality and, therefore, targeted populations thought to be at risk. This suggests either that the initial perceptions of communities at risk were incorrect or that behavioural and physiological coping strategies are very effective. Our own studies performed in the rural villages around Keneba, in The Gambia, (Prentice, 1984) have recorded some of the largest changes shown in Fig. 1 and therefore will be extensively cited.

\section{SEASONALITY OF CHILD GROWTH}

Fig. 2 shows an individual infant growth curve illustrating many of the features of seasonality common in the developing world (Rowland et al. 1981). The boy was born small but crossed centiles in the first 3-4 months of life when fully breast-fed and largely free from infections. The introduction of weaning foods and the onset of the rains led to the first clusters of infection. Between 4 and 9 months of age he gained no weight at all, and consequently fell far below the 50th centile. At the beginning of the next dry season, catch-up growth started again and continued until the next rains when growth once again 

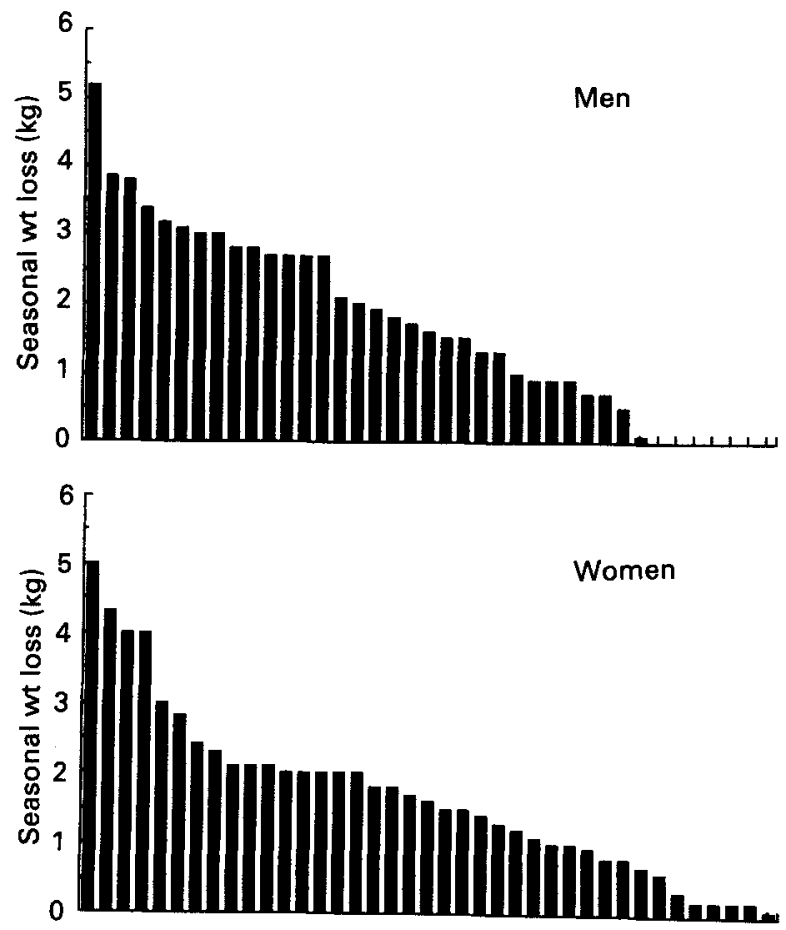

Published estimates in rank order

Fig. 1. Seasonal swings in adult body weight in regions of varying seasonality. Adapted from Ferro-Luzzi \& Branca (1993).

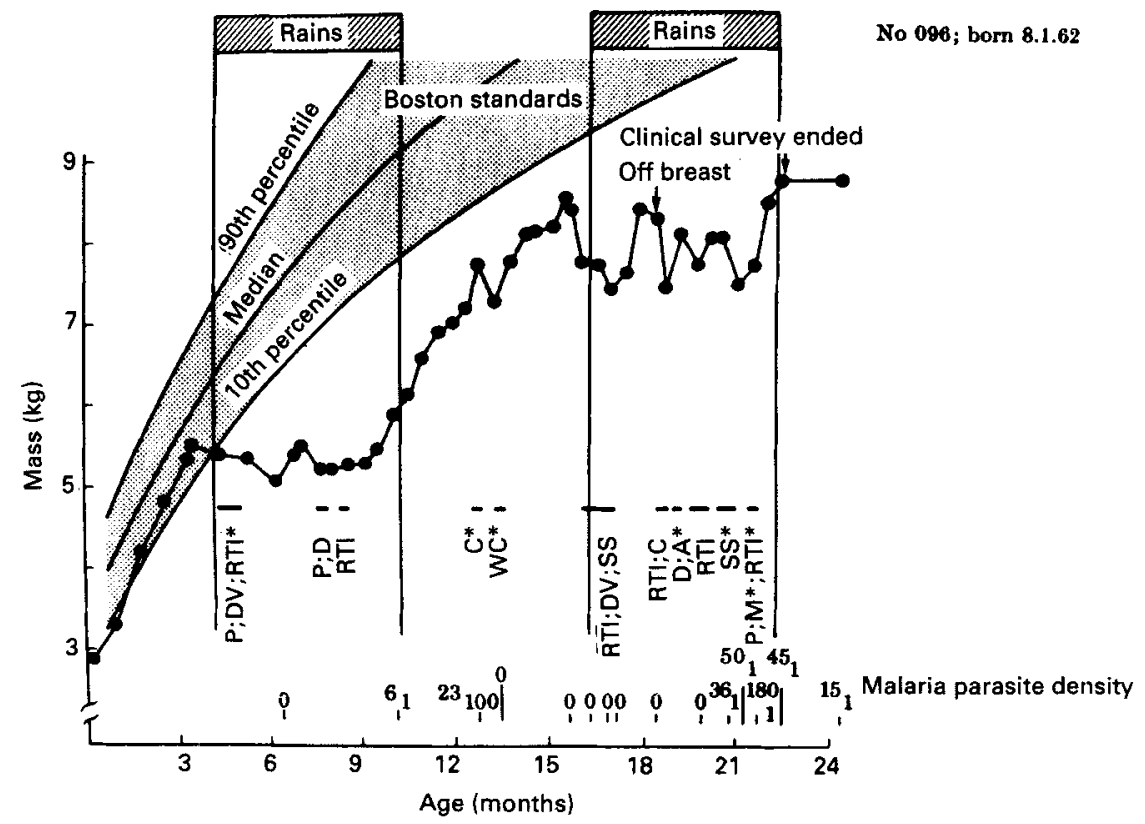

Fig. 2. Example of infant growth curve from rural Gambia. P, pyrexia; D, diarrhoea; V, vomiting; RTI, respiratory tract infection; C, conjunctivitis; WC, whooping cough; SS, skin sepsis (including abscess); A, ascariasis; M, malaria. * Specific treatment given. 
ceased for almost 8 months. Overall the wet season growth faltering outweighed the dry season catch-up resulting in a significantly undernourished child by the age of 2 years.

Seasonal growth faltering is caused by a variety of inter-related factors including raised levels of infection, deterioration in food availability and quality, and declining standards of child care. One of the major underlying factors in rural Gambia is the agricultural workload undertaken by mothers. They are frequently away from home for up to $8 \mathrm{~h} / \mathrm{d}$ and have to leave their infants in the care of a grandmother or elder sibling. Weaning foods, which are of especially poor quality in the wet season, may be made up early in the morning and left to be fed to the infant throughout the day. Warm, humid conditions provide an ideal environment for the growth of pathogenic organisms in these weaning gruels, and for their extended survival in the environment in general (Barrell \& Rowland, 1979). Average diarrhoea prevalence increases from around $5 \%$ in the dry season to over $20 \%$ in the wet season (Rowland et al. 1981).

In The Gambia, breast-milk intake declines by $10-15 \%$ in the wet season (Prentice et al. 1986). Although this coincides with the time of maternal food shortages and fat loss the link does not appear to be causal since the consumption of a high-energy supplement did not improve the mothers' breast-milk yields (Prentice et al. 1983b). We have concluded that it is more likely to be caused by a loss of appetite by the infants (secondary to their illnesses) and by the disruption to demand feeding patterns due to the long intervals that the women spend away from their infants when working in the fields (Prentice et al. 1986).

In spite of the varied factors contributing to seasonal weight faltering the overall impact is remarkably consistent from child to child, with the age at which each child falters being determined by its time of birth relative to the onset of the first rains. This is illustrated in Fig. 3 in which infants are divided into six groups according to their month of birth. The growth curves form an inter-weaving pattern which is even more evident when plotted as weight velocity (Fig. 3(b)). Length growth behaves in a similar manner, but the changes are less marked (Cole, 1993).

Many of the features of seasonal weight faltering seen in our Gambian studies are broadly applicable to other communities in the developing world. However, care should be taken not to over-generalize about the causes, magnitude or distribution of seasonality. For instance, a recent nationwide survey of seasonal changes in the incidence of malnutrition in Bangladesh (Helen Keller International, 1993) revealed very marked differences in the extent of seasonality between closely neighbouring regions of similar socio-economic status and climatic conditions. There also appeared to be no consistent association with urban or rural settings; both exhibited each end of the spectrum of seasonality ranging from almost no discernible trend to 3-4-fold swings in the proportion of children falling below $-2 \mathrm{Z}$ scores for weight-for-height. It is also worth noting that seasonality of child growth is not only confined to the developing world. It has been appreciated for many decades that sufficiently detailed longitudinal monitoring of child growth in affluent groups reveals a very distinct seasonal pattern with height growth tending to accelerate in the summer and weight growth accelerating in the winter (for example, see Palmer, 1933).

In some areas of the developing world child mortality rates are also highly seasonal. Fig. 4 shows just one example, from the Peanut Basin in Senegal, where death rates in the wet season are five to ten times higher than those in the dry season (Simondon et al. 1993). Similar variations occur in The Gambia (Billewicz \& MacGregor, 1981). Part of 

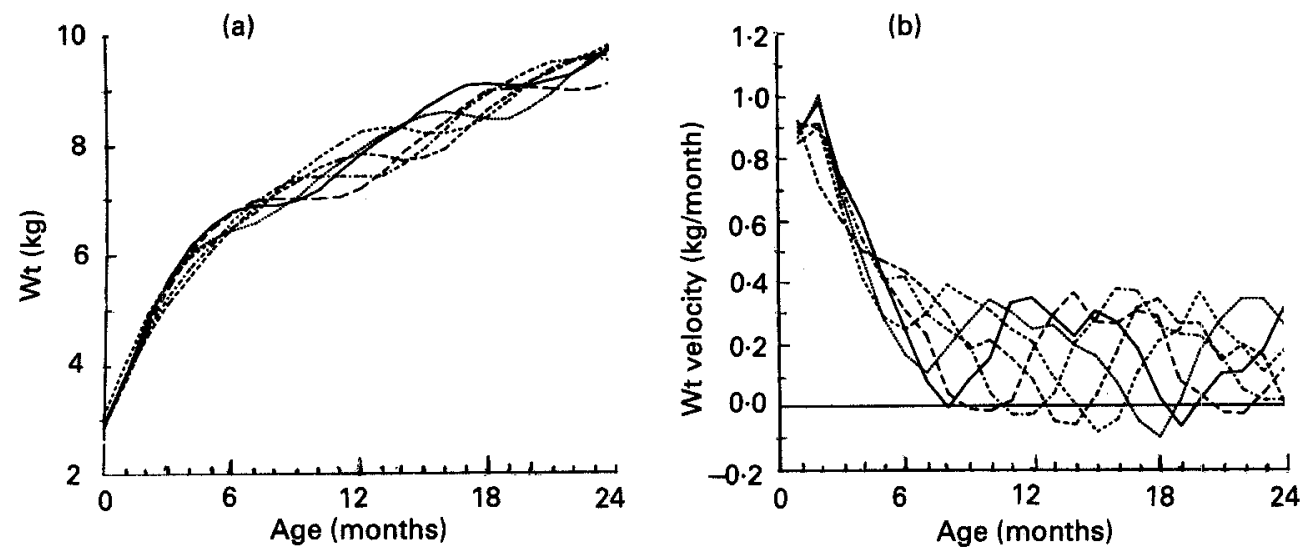

Fig. 3. Weight charts for Gambian children grouped by month of birth. (a), Absolute weight; (b), weight velocity. ( - ), December-January; (…), February-March; ( - - - ), April-May; ( - - ) ), June-July; ( $-\cdot--)$, August-September; ( $-\_-$), October-November. Adapted from Cole (1993).

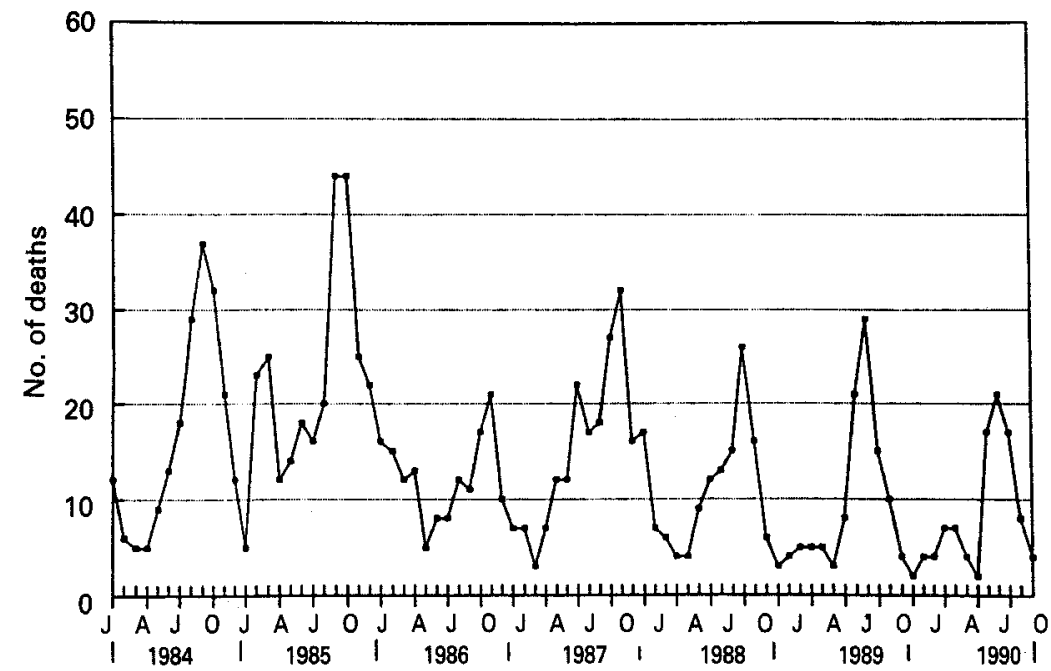

Fig. 4. Child mortality (0-4 years) in the Peanut Basin of Senegal. J, A, J, O, January, April, July, October respectively. Reproduced with permission from Simondon et al. (1993).

the seasonal variation in mortality is caused by seasonality in the transmission rates of life-threatening diseases such as malaria, but the children's debilitated nutritional state is a major contributory factor (Billewicz \& MacGregor, 1981).

\section{SEASONALITY OF ADULT ENERGY STATUS}

Some indication of the impact of season on adult energy status has already been provided in Fig. 1. Once again examination of our Gambian findings is useful both because of the depth of data available and because the seasonal effects are amongst the highest known. Fig. 5 shows the annual cycles of weight gain and loss measured in women of childbearing 


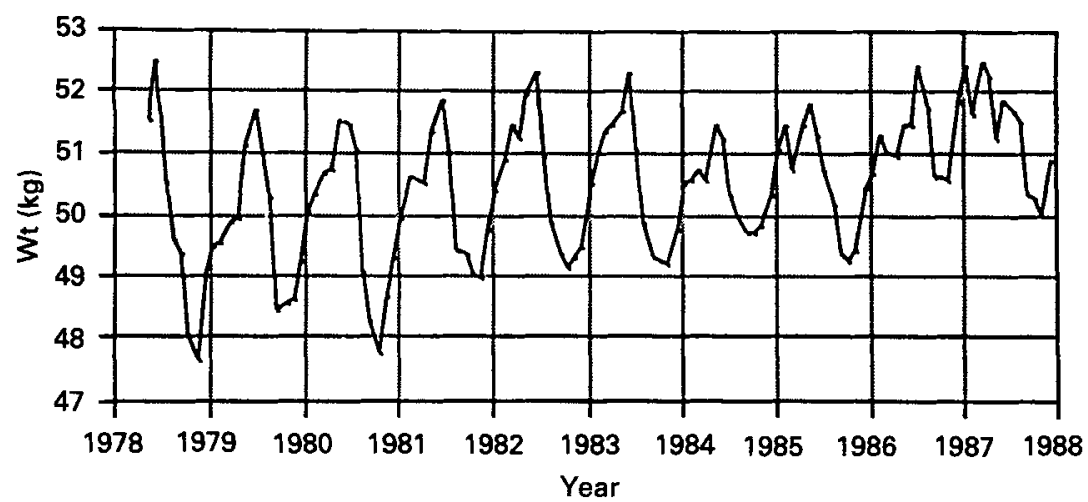

Fig. 5. Annual weight cycles in rural Gambian women.

age. The data include pregnant and lactating women, but the effects of reproductive cycle have been adjusted out by multiple-regression analysis (Cole, 1993). Several features emerge. First, that the extent of seasonality varies according to the year involved. In the late 1970s and early 1980s The Gambia was emerging from the Sahelian drought with gradually improving rainfall. The extent of seasonality diminished markedly. Second, it must be remembered that the swings illustrated in Fig. 5 represent average changes. In some women the changes were much greater and in others less. Third, it can be calculated that a swing of about $5 \mathrm{~kg} /$ year represents a mobilization of about $50 \%$ of body fat stores, since we have demonstrated by means of total body water measurements that there is little change in lean body mass (Prentice et al. 1992b). We have argued that these seasonal swings represent body fat functioning as nature intended, and that the 'yo-yo' dieting that is induced appears to be benign in the long term (Prentice et al. 1992a,b). In fact loss of lean tissue, often mooted as a detrimental outcome accompanying 'yo-yo' dieting, appears to be slower in Gambian men and women than in their Western counterparts (Prentice et al. 1992b).

As in the case of children, the causes of seasonal weight loss in adults are probably multifactorial, but with infections playing a much less prominent role. Estimates of the changes in food intake and energy expenditure in Gambian women are shown in Fig. 6. Early in the agricultural season the work output rises sharply as people clear and plough their fields, plant crops and do the early weeding. The later tasks such as crop guarding and harvesting are less strenuous. Food intake reaches its nadir in August before the availability of the first crop (maize in this community). This is caused primarily by the simple fact that most villagers have almost run out of their previous year's staple foods, but is compounded by the fact that the women are often too short of time and too tired to prepare more than one meal per day. The combination of these factors creates a negative energy balance resulting in the fat loss indicated in Fig. 6(b). One surprising feature of this pattern is that it is very difficult to reverse, even by means of intensive dietary supplementation (Prentice et al. 1983a). This has led to the suggestion that the very low fat content of the wet-season diet (about $15 \%$ of energy compared with about $25 \%$ in the dry season) combined with high levels of obligatory fat oxidation may play an important contributory role in determining the dynamics of fat loss (Sonko et al. 1993).

There has been considerable interest in the extent to which physiological and behavioural energy-sparing adjustments are invoked in an attempt to ameliorate energy 

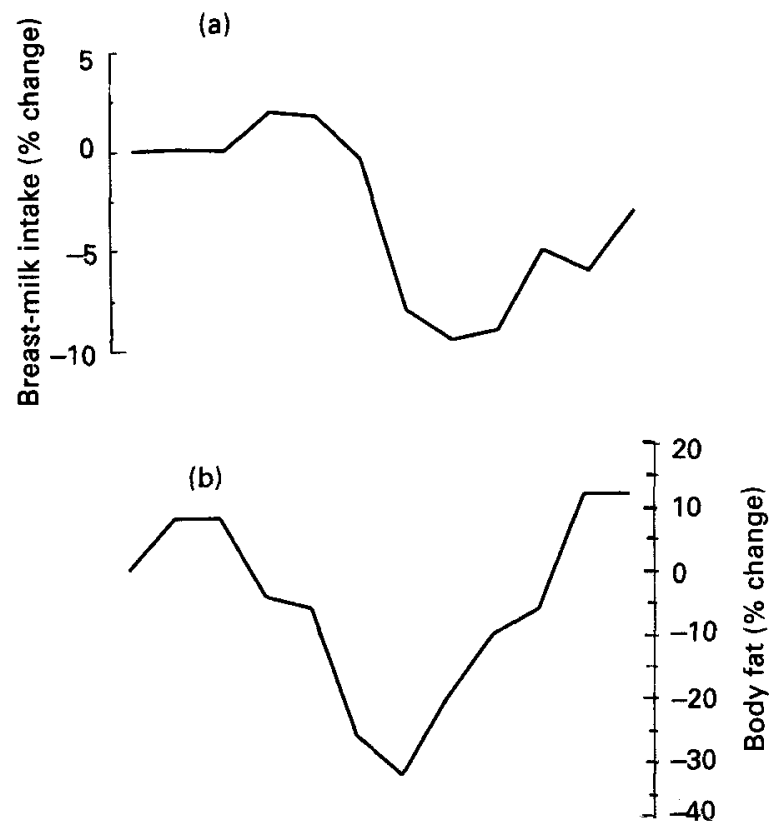

(c)

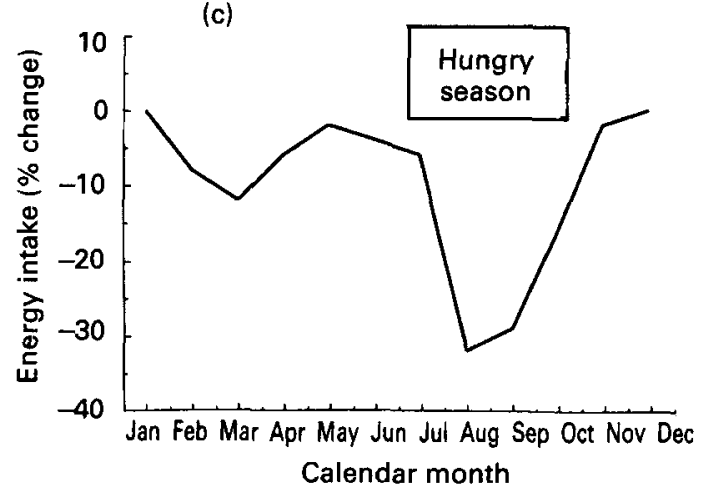

Fig. 6. Seasonal changes in energy intake, energy expenditure and body fat in rural Gambian women.

deficits. Both in Keneba (Lawrence \& Whitehead, 1988) and elsewhere (for example, see Ferro-Luzzi et al. 1988, 1990; Schultink et al. 1990) it has been demonstrated that basal metabolic rate does decrease during the hungry season, as would be predicted from the known effects of experimental energy restriction (Keys et al. 1950). However, the potential saving is only in the order of about $0.4 \mathrm{MJ}(100 \mathrm{kcal}) / \mathrm{d}$. There would be much greater scope for energy savings if physical activity were reduced, especially since it is generally at a very high level in rural farming communities. For instance, doubly-labelled water measurements of total energy expenditure (TEE) in Gambian women indicate a physical activity level ( $\mathrm{PAL}=\mathrm{TEE} / \mathrm{BMR}$ ) of about 2.0 in pregnant, lactating and non-pregnant women (Singh et al. 1987). This compares with PAL values of about 1.4-1.6 in typical Western women, indicating that the Gambians are approximately twice as active. In spite of this finding there seems to be very little indication that physical activity is suppressed in order to save energy and minimize weight loss. The reason is 
evidently that the obligate need to produce crops for the coming year takes greatest priority, and that fat loss is accepted as a survivable short-term penalty.

Dugdale \& Payne (1987) have examined whether this pattern of alternating feast and famine is a more effective survival mechanism than the theoretical alternative of adopting a more prudent intake over the whole of the year, thus avoiding an acute hungry season. The major disadvantage of the latter is that it incurs greater post-harvest crop losses. Dugdale \& Payne (1987) concluded that these could easily outweigh the short-term advantages of avoiding a partial famine, and that a fluctuating pattern of intake was, therefore, probably more efficient in a survival context. To this must be added the more human constraints such as the fact that it is of little personal advantage to save food for the wet season if others have been profligate with theirs, since social pressures then force the prudent villagers to support the less careful. Such factors are central to food insecurity and are likely to perpetuate seasonality until they can be overcome by conversion to a more cash-based economy, by improved social infrastructure, and by better crop yields.

\section{SEASONAL EFFECTS ON PREGNANCY AND FETAL GROWTH}

The effects of seasonality on human reproduction are particularly intriguing because they are likely to have a profound influence on genetic selection. In Keneba most women undergo ten to fifteen reproductive cycles, but child survival rates vary between 0 and $100 \%$ from woman to woman. Clearly this will lead to exceptionally heavy selective pressure in favour of the successful mothers. If part of their success is determined by the possession of metabolic traits which help them to carry a pregnancy through a period of moderately severe food shortage then such traits will rapidly predominate in the gene pool. Our studies of pregnant women have revealed that they do exhibit some remarkable energy-sparing metabolic adjustments in line with the previously stated prediction (Poppitt et al. 1993, 1994).

The interaction of a 12-month pattern of seasonality with a 9-month gestation period creates considerable complexity in the understanding of how fetal growth is affected by the changes in maternal energy status. The first effect of note is on the annual distribution of births which can be very uneven in areas of marked seasonality. Fig. 7 illustrates the highly significant variation in monthly birth rates from rural Gambia. Similar marked seasonality in birth rates has often been recorded elsewhere, for instance in Lesotho (Johnston, 1993). Fig. 7 shows that fewest births occur in the harvest season (May to July) and most in the hungry season (August to October). Thus, fewest conceptions occur at the height of the hungry season and most at the gathering of the harvest. This is in line with Frisch \& McArthur's (1974) concepts of suppressed fecundity in women who are nutritionally unprepared for pregnancy and have low fat stores, but might also be due to reduced coital frequency at a time of year when the demands of farm work are at their greatest. In fact, the data from The Gambia indicate that Frisch \& McArthur's (1974) proposed protective mechanism is paradoxically harmful due to the lack of synchrony between the human gestational cycle and the annual cycle. This is because the optimal time to be born is at the end of the harvest season when the most rapid fetal growth (occurring in the last trimester) can benefit from optimal maternal nutrition, but it is then that the fewest births occur. Both neonatal (Billewicz \& MacGregor, 1981) and childhood (A. M. Prentice, unpublished results) mortality rates 


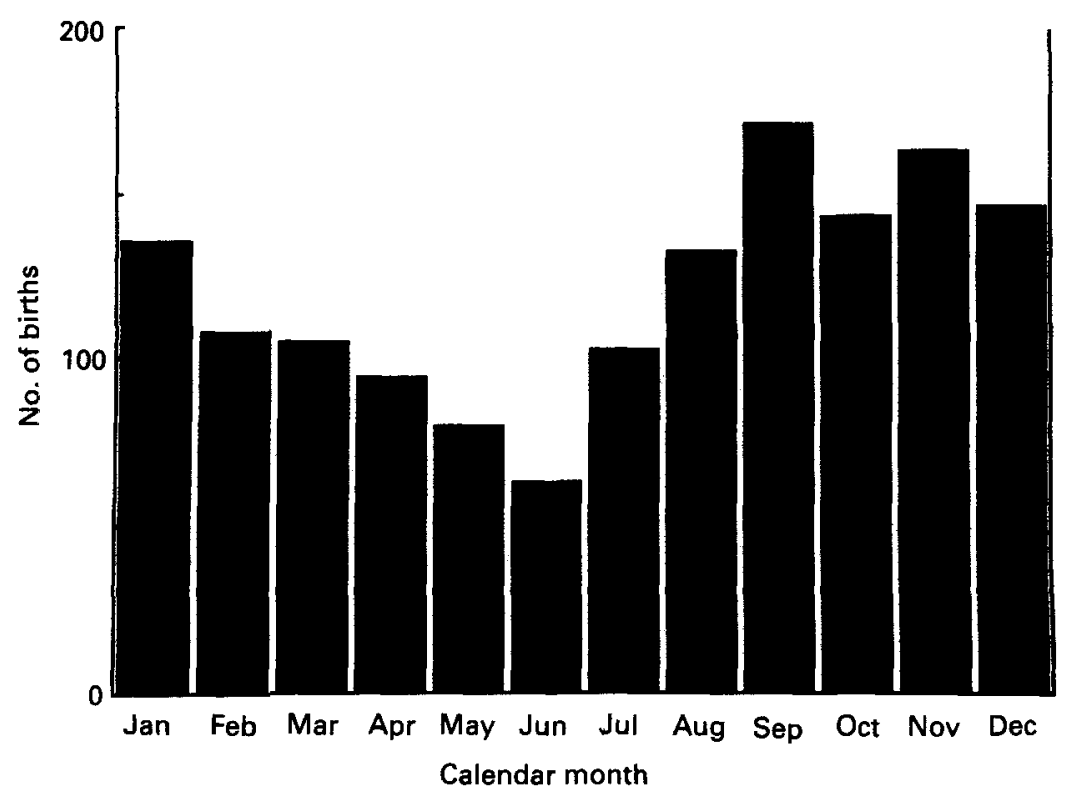

Fig. 7. Variation in monthly birth rates in rural Gambia.

are more than twice as great for hungry-season births than for harvest-season births. Thus, the supposed 'protective' mechanism is anything but protective.

The effects of seasonality on maternal weight gain in pregnancy are also paradoxical. If judged over the whole of gestation, women who deliver in the hungry season have the highest cumulative weight gain since the majority of their pregnancy has been carried during the harvest months, and vice versa. Normally a high weight gain would be associated with larger babies, but this is not the case. Hungry-season babies are significantly smaller than those born during the rest of the year, and there is a much higher proportion of low-birth-weight babies (Prentice et al. 1987). The peak-to-trough swing in birth weight in Keneba is about $300 \mathrm{~g}$. The dissociation of the normal link between pregnancy weight gain and birth weight occurs because the fetus is very sensitive to acute growth retardation at the end of pregnancy when it is growing most rapidly (Stein et al. 1975). In the worst months of August and September in The Gambia women actually lose weight, on average, during pregnancy in spite of the fact that they are attempting to accrue new tissue in the products of conception.

Detailed longitudinal measurements of the metabolic costs of pregnancy have now been made in a large number of women from varied nutritional settings around the world (Poppitt et al. 1994). Our own measurements from Keneba represent the most nutritionally disadvantaged population yet studied and the only one with pronounced seasonality. We have demonstrated a very marked energy-sparing suppression of metabolic rate during pregnancy in Gambian women (Poppitt et al. 1993). Meta-analysis of all the available data indicates that these metabolic adjustments are influenced by a mother's energy status at the time of conception and by her energy balance during pregnancy, and that they probably represent a powerful means of protecting fetal growth (Poppitt et al. 1994). We believe that seasonality may have had an important influence on the evolution of these adaptive responses since, as argued previously, the pressure in favour of their selection would be great. 


\section{AFFLUENT SOCIETY'S INHERITANCE FROM SEASONALITY}

Seasonality of the type described previously has probably been the norm over much of human evolution in both hunter-gatherer and agrarian communities, and has probably been an important factor in the selection of more general survival traits than those described for pregnancy. Man's generous body fat reserves represent one strategy for coping with alternating feast and famine (Prentice et al. 1992a). Under conditions of fluctuating food supply the ability to deposit fat rapidly at times of plenty is probably beneficial. These energy reserves are themselves conserved by energy-sparing reductions in metabolic rate which switch in almost as soon as food intake is restricted (Keys et al. 1950). Such mechanisms are now regretted in affluent societies which have a major problem with obesity.

It has been suggested also that a number of metabolic disorders associated with affluence (e.g. non-insulin-dependent diabetes mellitus (NIDDM)), similarly, may be caused by the interaction of a now redundant 'thrifty genotype' with a diet which is no longer ever in short supply. The concept of a thrifty gene, which may confer survival benefit during seasonal food shortages, is rather poorly defined, but probably serves as a useful framework to explain the consequences of a transition from a meagre and seasonally deficient diet to one of constant availability. In certain populations which have undergone a very rapid acculturation the prevalence of NIDDM reaches almost $100 \%$, and in countries such as the UK NIDDM is much more common in first and second generation immigrants from developing countries than in the indigenous stock.

It is interesting to note that there is little selective pressure towards the reversal of these thrifty traits since almost all the associated mortality affects men and women after their reproductive age.

\section{SEASONALITY AS THE FORERUNNER OF FAMINE}

Thus far, we have described seasonality as a relatively benign phenomenon, at least in adults. It must be remembered, however, that it is only benign so long as each hungry season is immediately relieved by a harvest. If crops fail, starvation ensues very rapidly because people have already suffered many months in which they have been forced to draw on their body fat reserves in order to subsidize a deficit energy budget. Early warning of crop failures is, therefore, of paramount importance in highly seasonal regions.

\section{REFERENCES}

Barrell, R. A. E. \& Rowland, M. G. M. (1979). Infant foods as a potential source of diarrhoeal illness in rural West Africa. Transactions of the Royal Society of Medicine and Hygiene 73, 85-90.

Billewicz, W. Z. \& MacGregor, I. A. (1981). The demography of two West African (Gambian) villages 1951-75. Journal of Biosocial Science 13, 219-240.

Cole, T. J. (1993). Seasonal effects on physical growth and development. In Seasonality and Human Ecology, pp. 89-106 [S. J. Ulijaszek and S. S. Strickland, editors]. Cambridge: Cambridge University Press.

Dugdale, A. E. \& Payne, P. R. (1987). A model of seasonal changes in energy balance. Ecology of Food and Nutrition 19, 231-245.

Ferro-Luzzi, A. \& Branca, F. (1993). Nutritional seasonality: the dimensions of the problem. In Seasonality and Human Ecology, pp. 149-165 [S. J. Ulijaszek and S. S. Strickland, editors]. Cambridge: Cambridge University Press. 
Ferro-Luzzi, A., Pastore, G. \& Sette, S. (1988). Seasonality in energy metabolism. In Chronic Energy Deficiency: Consequences and Related Issues, pp. 37-58 [B. Schürch and N. S. Scrimshaw, editors]. Lausanne: IDECG.

Ferro-Luzzi, A., Scaccini, C., Taffese, S., Aberra, B. \& Demeke, T. (1990). Seasonal energy deficiency in Ethiopian rural women. European Journal of Clinical Nutrition 44, Suppl. 1, 7-18.

Frisch, R. E. \& McArthur, J. W. (1974). Menstrual cycles: fatness as a determinant of minimum weight for height necessary for their maintenance or onset. Science 185, 949-951.

Helen Keller International (1993). Seasonality of Nutritional Status in Bangladesh. Dhaka, Bangladesh: Helen Keller International.

Johnston, F. E. (1993). Seasonality and human biology. In Seasonality and Human Ecology, pp. 5-166 [S. J. Ulijaszek and S. S. Strickland, editors]. Cambridge: Cambridge University Press.

Keys, A., Brozek, J., Henschel, A., Mickelsen, O. \& Taylor, H. L. (1950). The Biology of Human Starvation. Minneapolis: University of Minnesota Press.

Lawrence, M. \& Whitehead, R. G. (1988). Physical activity and total energy expenditure of child.bearing Gambian village women. European Journal of Clinical Nutrition 42, 145-160.

Palmer, C. E. (1933). Seasonal variation of average growth in weight of elementary school children. United States Public Health Reports 48, 211-234.

Poppitt, S. D., Prentice, A. M., Goldberg, G. R. \& Whitehead, R. G. (1994). Energy-sparing strategies to protect human fetal growth. American Journal of Obstetrics and Gynecology (In the Press).

Poppitt, S. D., Prentice, A. M., Jéquier, E., Schutz, Y. \& Whitehead, R. G. (1993). Evidence of energy sparing in Gambian women during pregnancy: a longitudinal study using whole-body calorimetry. American Journal of Clinical Nutrition 57, 353-364.

Prentice, A. M. (1984). Adaptations to long-term low energy intake. In Current Topics in Nutrition and Disease. Vol. 2, Energy Intake and Activity, pp. 1-31 [E. Pollitt and P. Amante, editors]. New York: Alan R. Liss Inc.

Prentice, A. M., Cole, T. J., Foord, F., Lamb, W. H. \& Whitehead, R. G. (1987). Increased birthweight following prenatal dietary supplementation of rural African women. American Journal of Clinical Nutrition 46, 912-925.

Prentice, A. M., Diaz, E., Goldberg, G. R., Jebb, S. A., Coward, W. A. \& Whitehead, R. G. (1992a). Famine and refeeding: adaptations in energy metabolism. In The Biology of Feast and Famine: Relevance to Eating Disorders, pp. 245-267 [G. H. Anderson and S. H. Kennedy, editors]. San Diego: Academic Press.

Prentice, A. M., Jebb, S. A., Goldberg, G. R., Coward, W. A., Murgatroyd, P. R., Poppitt, S. D. \& Cole, T. J. (1992b). Effects of weight cycling on body composition. American Journal of Clinical Nutrition 56, Suppl. 1, 209S-216S.

Prentice, A. M., Lunn, P. G., Watkinson, M. \& Whitehead, R. G. (1983a). Dietary supplementation of lactating Gambian women. 2. Effect on maternal health, nutritional status and biochemistry. Human Nutrition: Clinical Nutrition 37C, 65-74.

Prentice, A. M., Paul, A. A., Prentice, A., Black, A. E., Cole, T. J. \& Whitehead, R. G. (1986). Cross-cultural differences in lactational performance. In Maternal Environmental Factors in Human Lactation, pp. 13-44 [M. Hamosh and P. Hamosh, editors]. New York: Plenum Press.

Prentice, A. M., Roberts, S. B., Prentice, A., Paul, A. A., Watkinson, M., Watkinson, A. A. \& Whitehead, R. G. (1983b). Dietary supplementation of lactating Gambian women. 1. Effect on breast-milk volume and quality, Human Nutrition: Clinical Nutrition 37C, 53-64.

Rowland, M. G. M., Paul, A. A., Prentice, A. M., Muller, E. M., Hutton, M., Barrell, R. A. E. \& Whitehead, R. G. (1981). Seasonality and growth of infants in a Gambian village. In Seasonal Dimensions to Rural Poverty, pp. 164-175 [R. Chambers, R. Longhurst and A. Pacey, editors]. London: Francis Pinter (Publishers) Ltd.

Schultink, W. J., Klaver, W., van Wijk, H., van Raaij, J. M. A. \& Hautvast, J. G. A. J. (1990). Body weight changes and basal metabolic rates of rural Beninese women during seasons with different energy intakes. European Journal of Clinical Nutrition 44, Suppl. 1, 31-40.

Simondon, K. B., Bénéfice, E., Simondon, F., Delaunay, V. \& Chahnazarian, A. (1993). Seasonal variation in nutritional status of adults and children in rural Senegal. In Seasonality and Human Ecology, pp. 166-183 [S. J. Ulijaszek and S. S. Strickland, editors]. Cambridge: Cambridge University Press.

Singh, J., Prentice, A. M., Diaz, E., Coward, W. A., Ashford, J., Sawyer, M. \& Whitehead, R. G. (1987). Energy expenditure of Gambian women during peak agricultural activity measured by the doubly-labelled water method. British Journal of Nutrition 62, 315-329. 
Sonko, B. J., Prentice, A. M., Paul, A. A., Prentice, A. M., Schutz, Y., Jéquier, E. \& Whitehead, R. G. (1993). The importance of dietary fat in maintaining energy balance in a rural subsistence farming community. Proceedings of the Nutrition Society 52, $48 \mathrm{~A}$.

Stein, Z., Susser, M., Saenger, G. \& Marolla, F. (1975). Famine and Human Development: The Dutch Hunger Winter of 1944-1945. Oxford: Oxford Medical Publications. 